\title{
Issues in Assessment of Children Who Stutter: A Survey of Speech-Language Pathologists in the State of North Carolina
}

\author{
Patrick Minton Briley \\ Department of Communication Sciences \& Disorders, East Carolina University, Greenville, NC, United States
}

Purpose: To survey school-based speech-language pathologists (SLPs) in the state of North Carolina (NC) to examine management practices primarily related to their work with children who stutter (CWS) and to identify factors that influence their assessment approaches.

Methods: Data were obtained from a statewide survey of school-based SLPs in NC. SLPs responded to questions pertaining to their experience, confidence, and approaches to management of CWS. The data analysis approach for this project was primarily descriptive, while Chi-square tests of independence were used for comparing categorical variables.

Results: Four hundred forty-four SLPs, with an average of 16.1 years of experience, participated in the project. Fifty-seven percent of the sample reported being extremely confident in the screening process for CWS, $47 \%$ were extremely confident in evaluating CWS, but only $14 \%$ were extremely confident in treating CWS. The Stuttering Severity Instrument (SSI) is the most commonly utilized tool for evaluations. Seventy-nine percent of the respondents evaluate for the presence of covert behaviors, and $81 \%$ of the sample requires the presence of overt stuttering behaviors in order to recommend treatment for stuttering.

Conclusions: Data from this survey revealed that many SLPs in this sample lack, to some degree, confidence in managing CWS, which has direct clinical implications. These results suggest a need to understand the reasons behind this lack of confidence and a need to continue working towards a more comprehensive understanding of the disorder in its entirety. Doing so will ultimately contribute to enhanced management practices and improved outcomes in CWS.

Keywords: Stuttering, Confidence, Covert Behaviors, Overt Behaviors

\section{INTRODUCTION}

Stuttering is a communication disorder that typically emerges before a child reaches school-age [1]. The incidence of this disabling disorder is generally accepted to be around 5\% of the United States' (U.S.) population [2]. Evidence also suggests the prevalence of stuttering decreases over time due to natural recovery [2]. The consequences of stuttering can be a debilitating influence on people who stutter (PWS). The negative influence of stuttering extends beyond the overt manifestations of stuttering such as sound and word repetitions, sound prolongations, and audible and inaudible postural fixations [2]. Specifically, the experience of stuttering also includes inconspicuous behaviors that are not observable to listeners. These include avoidances of sounds, words,

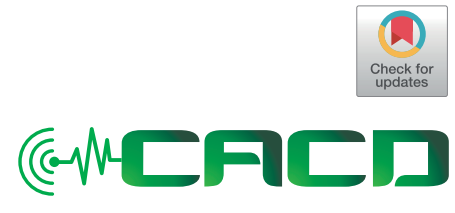

Received: May 5, 2018 Accepted: August 26, 2018

\section{Correspondence:} Patrick Minton Briley

Department of Communication Sciences \& Disorders, East Carolina University, 2310C Health Sciences Building, MS 668 Greenville, NC 27834, United States Tel: +252-744-6111

Fax: +252-744-6109 E-mail: brileypa@ecu.edu

(C) 2018 The Korean Association of SpeechLanguage Pathologists

This is an Open Access article distributed under the terms of the Creative Commons Attribution NonCommercial License (http://creativecommons.org/ licenses/by-nc/4.0/) which permits unrestricted noncommercial use, distribution, and reproduction in any medium, provided the original work is properly cited. 
people, and places [2]; subperceptual stuttering [3]; and anticipation of stuttering [4]. Collectively, the range of behaviors that individuals who stutter experience can result in dramatic reductions in quality of life, vitality, social functioning, and emotional well-being [5].

Despite the longstanding history of research related to stuttering, questions seem to remain regarding best practices for stuttering management. These questions are potentially due to the complexity of issues required for successful management that extend beyond the frequently observed speech production difficulties. For example, Yaruss, Coleman, and Quesal [6] note that optimal stuttering management requires clinicians to utilize a comprehensive approach that addresses characteristics of stuttering beyond the most common observable behaviors. Because of the complex nature of stuttering, diverse philosophies on how to best manage stuttering have emerged over time and resulted in substantial variability in management practices [6-9]. Consequently, there is potential for commonly used approaches in the management of stuttering to vary greatly based on training, experience, and theoretical/philosophical beliefs about stuttering $[10,11]$. Therefore, the divergent range of philosophies about stuttering management has resulted in a similarly divergent range of assessment and treatment approaches [12].

Regarding stuttering assessment specifically, a key emphasis of many stuttering evaluations is the measurement of observable speech disfluencies. Assessment approaches emphasizing observable disfluencies give foremost consideration to the frequency of disfluencies, the duration of those disfluencies, and related atypical observable speech production behaviors, though this approach may not offer the thoroughness required to optimally evaluate the complex nature of stuttering in full (i.e., observable and unobservable characteristics). In a scenario where the assessment is primarily focused on the specific behaviors that are perceivable to the speech-language pathologist (SLP), there is potential of not accurately identifying the true impact of the disorder. One reason for this is due to the day-to-day and situation-to-situation variability of observable behaviors of stuttering [13]. An assessment approach emphasizing the overt manifestation of the disorder may also predispose an evaluator to overlook other behaviors; namely, those that are not readily observable. Therefore, assessment approaches lacking a focus on both observable and unobservable stuttering behaviors can fail to account for the true impact of stuttering on involvement in daily activities and overall quality of life [14]. Identification of unobservable be- haviors (e.g., avoidances of sounds, words, people, places, and situations) is vitally important in the assessment of children who stutter (CWS) because they are known to negatively impact the speaker's quality of life by contributing to the embarrassment and communicative restrictions resulting from stuttering [15]. In summary, stuttering is a complex disorder where evaluation approaches and commonly available tools are at their best when they evaluate the diverse range of symptoms that negatively impact individuals who stutter.

There are a number of factors that possibly contribute to the potential limitations of stuttering evaluations. First, recent evidence suggests that the training necessary to ensure clinicians are adequately prepared to manage stuttering clients is less than optimal. According to Tellis, Bressler, and Emerick [16], many speech-language pathologists do not possess the requisite knowledge related to the assessment and treatment of stuttering. For example, some SLPs have shown a lack of understanding of the interplay between stuttering's neurological underpinnings and its influence on psychological and motoric propensities $[17,18]$. Consequently, they are not prepared to address the diversity of factors related to issues associated with the disorder. Second, there is some evidence that clinicians treating CWS lack not only detailed knowledge of stuttering [19], but they also have limited opportunities to obtain the necessary experience and confidence required to successfully manage CWS [20].

Therefore, issues related to stuttering management are potentially associated with the tools and approaches that are being used during assessments and the experience, knowledge, and confidence of the SLPs that are conducting these assessments. To explore these issues, this study was designed to survey school-based clinicians in the state of North Carolina to examine their experience, confidence, and approaches to management of CWS. According to NC public school guidelines, current standards for fluency assessments include numerous variables, but the following are of note: information obtained from teachers on communication skills, behavior, and social skills; coping mechanisms; and covert stuttering behaviors [21]. Additionally, the following guidelines are in place for consideration of observable behaviors, where the presence of one is required along with a co-occurring adverse effect on educational performance: 1a) greater than $2 \%$ stuttered-like disfluencies; or $1 \mathrm{~b}$ ) greater than $5 \%$ stuttered-like disfluencies or covert stuttering behaviors; or 2) rate of speech 1.5 standard deviations from the mean; or 3) Speech naturalness outside the normal range on a 9-point naturalness rating 
scale [21]. Once an assessment is complete, the Fluency Severity Rating Scale is available to assist in assigning a severity level to the stuttering behaviors, to confirm whether or not educational performance is being adversely impacted, and ultimately if the CWS meets eligibility to receive therapy [21]. Therefore, while this rating scale does assist in making a determination of service for the CWS, it does not assist the clinician in differentiating between overt and covert severity levels.

Examination of management issues among SLPs currently working with this population may allow identification of strengths of current practices and areas where improvements can be made. The goal of this project is to highlight barriers and facilitators associated with clinicians and commonly used assessment approaches to provide contribution to advancement towards optimal stuttering management.

\section{METHODS}

\section{Survey sample and plan of administration}

This study was reviewed and approved by the East Carolina University Institutional Review Board (IRB). A cross-sectional design was utilized to gather data from a statewide sample of school-based licensed and certified SLPs from the state of North Carolina. The survey was administered via REDCap electronic data capture tools [22]. REDCap (Research Electronic Data Capture) is a secure, web-based application designed to support data capture for research studies, providing: 1) an intuitive interface for validated data entry; 2) audit trails for tracking data manipulation and export procedures; 3) automated export procedures for seamless data downloads to common statistical packages; and 4) procedures for importing data from external sources. All potential participants were identified via North Carolina public school websites, and they were sent invitations and instructions on how to complete and submit the survey. Participation reminder emails were sent at seven and 14 days after the initial invitation.

\section{General survey format}

The instrument used for this survey was designed to identify: a) SLPs' clinical background and experience; b) their caseload characteristics; c) their confidence in working with CWS; and d) characteristics of their assessments of CWS (See Appendix).

\section{Data analysis}

SPSS Version 22 was used for statistical analysis [23]. The data analysis approach for this project was primarily descriptive.
Additionally, analyses were conducted to explore the effect of a combination of variables on various measurements. For comparisons between SLPs' years of experience and confidence levels, years of experience were reported in three categories: 0-10, 11-20, and over 20 years. Chi-square test of independence was used for comparing categorical variables.

\section{RESULTS}

\section{SLP background and caseload characteristics}

For background and caseload characteristics of SLPs included in the study, the average presence of each variable is presented in percentages to provide an account of the sample. Of the 1,173 school-based SLPs in the state of North Carolina who were sent a survey invitation, 444 (37.9\%) SLPs submitted a survey. Ninety-one percent of respondents reported having a stand-alone graduate course in fluency/stuttering disorders. The number of years the SLPs have been practicing ranged from under one year to 40 years $(M=16.1, S D=10.1)$. The average size of caseloads of the 442 responding SLPs ranged from 12 children to 90 children $(M=46.6, S D=10.5)$, and the number of CWS on SLPs' caseloads ranged from 0 to 10 $(M=2.2, S D=1.6)$. Additional information was provided by $95 \%$ of the 381 SLPs who currently have CWS on their caseloads. These SLPs classified $52 \%$ of the CWS as mild, $36 \%$ as moderate, and $12 \%$ as severe. Over the past 12 months, the number of completed screenings $(M=1.5, S D=1.4)$ and completed evaluations $(M=1.1, S D=1.1)$ performed on suspected CWS ranged from zero to 6 .

\section{Confidence of SLPs when working with CWS}

Fifty-seven percent of the sample indicated they were extremely confident in screening for the presence of stuttering. Similarly, $47 \%$ were extremely confident in evaluating for the presence of stuttering. Confidence levels were substantially lower for treating CWS where, in contrast, only $14 \%$ were extremely confident in treating CWS and notably $16.9 \%$ were not at all confident (Table 1). When comparing level of confidence across years of experience, there were significant differences in SLPs confidence in screening and evaluating for the presence of stuttering. Percentages of SLPs who are extremely confident in screening for the presence of stuttering was greatest in SLPs with over 20 years of experience (63\%), which was significantly higher than those with 0 -10 years of experience (50.3\%), $\left(\chi^{2}(4, N=439)=13.42, p=0.009\right.$. Similarly, percentages of SLPs who are extremely confident in evaluating 
Table 1. Confidence of SLPs when working with CWS

\begin{tabular}{|c|c|c|c|c|c|}
\hline & \multirow[b]{2}{*}{$\begin{array}{c}\text { Total } \\
\text { (439 SLPs) }\end{array}$} & \multicolumn{4}{|c|}{ Years of experience } \\
\hline & & $\begin{array}{l}0-10 \text { years } \\
\text { (153 SLPs) }\end{array}$ & $\begin{array}{l}11-20 \text { years } \\
\text { (142 SLPs) }\end{array}$ & $\begin{array}{l}\text { Over } 20 \text { years } \\
\text { (144 SLPs) }\end{array}$ & $p$-value \\
\hline \multicolumn{6}{|c|}{ Confidence in screening for the presence of stuttering: } \\
\hline Not at all confident & 1.8 & 4.6 & 0.7 & 0 & \multirow{3}{*}{0.009} \\
\hline Somewhat confident & 41.0 & 45.1 & 40.8 & 36.8 & \\
\hline Extremely confident & 57.2 & 50.3 & 58.5 & 63.2 & \\
\hline \multicolumn{6}{|c|}{ Confidence in evaluating for the presence of stuttering: } \\
\hline Not at all confident & 4.3 & 7.8 & 3.5 & 1.4 & \multirow{3}{*}{0.008} \\
\hline Somewhat confident & 48.5 & 53.6 & 48.6 & 43.1 & \\
\hline Extremely confident & 47.2 & 38.6 & 47.9 & 55.6 & \\
\hline \multicolumn{6}{|c|}{ Confidence in treating CWS: } \\
\hline Not at all confident & 16.9 & 19.6 & 17.6 & 13.2 & \multirow{3}{*}{0.573} \\
\hline Somewhat confident & 69.2 & 68.6 & 68.3 & 70.8 & \\
\hline Extremely confident & 13.9 & 11.8 & 14.1 & 16.0 & \\
\hline
\end{tabular}

SLP, speech-language pathologist; CWS, children who stutter.

for the presence of stuttering was greatest in SLPs with over 20 years of experience (55.6\%), which again was significantly greater than those with 0 -10 years of experience $(38.6 \%),\left(\chi^{2}(4\right.$, $N=439)=13.72, p=0.008$. However, there was not a significant difference in comparing SLPs' years of experience with confidence level in treating CWS, $\left(\chi^{2}(4, N=439)=2.91, p=0.0573\right.$. Table 1 for a breakdown of confidence levels across years of experience.

\section{Assessment of stuttering}

Evaluation tools used by SLPs in the assessment of stuttering

The most commonly used tool was the SSI-4 or an earlier version. Versions of the SSI were utilized by three hundred ninety-one SLPs (90.1\%), used either as the sole instrument or in conjunction with another instrument/method. Eightyseven SLPs $(20.0 \%)$ reported using more than one standardized tool, and 35 SLPs (8.1\%) indicated that their only evaluation method was through informal assessment (Table 2).

\section{SLPs' considerations when evaluating CWS}

Approximately $79 \%$ of SLPs reported evaluating covert behaviors of stuttering, and 229 SLPs (52.5\%) also assigned severity levels to covert behaviors. Differences in utilization of assessment tools were observed between those SLPs who assess covert behaviors and those SLPs who do not assess covert behaviors. Those SLPs who do not assess covert behaviors were more likely to solely utilize a version of the SSI (53.9\%) compared to those who do assess covert behaviors (33.6\%), $\left(\chi^{2}(1\right.$,
Table 2. Evaluation tools used by SLPs in the evaluation of stuttering

\begin{tabular}{lc}
\hline & $\begin{array}{c}\text { SLP } \\
\text { Respondents } \\
\text { ( } \mathrm{n}=434) \\
\text { Percent }\end{array}$ \\
\hline Stuttering severity instrument - (All editions) & 90.1 \\
SSI (All Editions) only & 41.9 \\
SSI (All Editions) and informal assessments only & 36.1 \\
SSI (All Editions) and other standardized assessments & 22.0 \\
Perceptions of stuttering inventory (PSI) & 7.8 \\
Overall assessment of the & 6.0 \\
speaker's experience of stuttering (OASES) & 5.5 \\
Test of childhood stuttering (TOCS) & 4.1 \\
Stuttering prediction instrument for young children (SPI) & 1.8 \\
The cognitive, affective, linguistic, & \\
motor, and social (CALMS) assessment & 0.2 \\
Behavior assessment battery for & 1.6 \\
school-age children who stutter (BAB) & 8.1 \\
\hline Other standardized assessments & \\
Informal assessment only & \\
\hline
\end{tabular}

SLP, speech-language pathologist.

$N=431)=12.38, p<0.001)$. There were no significant differences in SLPs' level of confidence in evaluating stuttering when comparing those who evaluate covert behaviors and those who do not, $\left(\chi^{2}(2, N=433)=2.88, p=0.237\right.$. However, differences were present in confidence levels in treating stuttering when comparing those SLPs who evaluate covert behaviors and are extremely confident in providing treatment 
Table 3. SLPs' considerations when evaluating CWS

\begin{tabular}{lc}
\hline & $\begin{array}{c}\text { SLP } \\
\text { respondents } \\
\text { Percent }\end{array}$ \\
\hline Do you evaluate covert behaviors? ( $\mathrm{n}=436)$ & 79.1 \\
Do you assign severity to covert behaviors? ( $\mathrm{n}=436)$ & 52.5 \\
Who indicated that observable disfluencies were & 80.6 \\
needed in order to place a child for stuttering services & \\
(n=350) & \\
Those indicating what \% they require (188 SLPs) & 21.9 \\
Who require the presence of less than 5\% & 24.6 \\
Who require the presence of at least 5\% & 25.4 \\
Who require the presence of at least 10\% & 16.5 \\
Who require the presence of at least 20\% & 11.7 \\
Who require the presence of at least 30\% &
\end{tabular}

SLP, speech-language pathologist; CWS, children who stutter.

for CWS (16.6\%) and those SLPs who do not evaluate covert behaviors and are extremely confident in providing treatment (4.4\%), $\left(\chi^{2}(2, N=434)=10.73, p=0.005\right)$. In addition, 282 of 350 respondents (80.6\%) indicated that disfluencies must be present in order for a child to qualify for services to treat stuttering. Of those 282 SLPs, 188 (66.7\%) reported a specific percentage required to qualify a CWS for services. Percentages required to qualify CWS for services $(M=12.7, S D=11.3)$ ranged from $1 \%$ to $50 \%$ (Table 3 ). There were no significant differences across years of experience in those SLPs requiring that disfluencies be present to qualify a CWS for therapy, $\left(\chi^{2}(2, N=349)\right.$ $=0.647, p=0.723$ ).

\section{DISCUSSION}

The key finding of this survey is the confidence in stuttering management is lacking in many SLPs despite many years of experience in the field of speech-language pathology. Data from this survey showed that a large percentage were extremely confident in screening and evaluating CWS, but only a small percentage reported being extremely confident in treating stuttering. One potential explanation for the lack of concordance between years of experience and confidence in stuttering management may be related to clinical training and/or experiences in working with PWS. Data from the current project highlights one potential source of inexperience, as the maximum number of stuttering evaluations over the past 12 months conducted by any SLP was 6 , with a mean of just over one. A tenable conclusion is this lack of exposure to this client population does not readily allow for one to build clinical expertise in the assessment of stuttering. This project provides preliminary support to this possibility, as there were significant differences in SLPs' confidence levels in screening and evaluating for the disorder based on experience, and the general trend was an increase in confidence levels with an increase in years of experience. The mean number of CWS on SLPs caseload was just over two, representing a client population of fewer than $5 \%$ of the SLPs' total caseloads. As with confidence in assessing stuttering, the minimal opportunities for SLPs to work with CWS (i.e., mean of 2.2 on current caseloads) may influence confidence levels when treating CWS. Interestingly, SLPs did not differ significantly in their confidence in treating stuttering with increased experience. The exact reason for increased experience not providing an increase in confidence when treating CWS is not clear and should be explored in future works. While SLPs are more confident in their abilities to evaluate stuttering than to treat it, one may argue that a lack of confidence in treatment may also be indicative of uncertainties about the full nature of the disorder. That is, hesitancies regarding treatment may be a result of a broader uncertainty that, realized or not, may be influential throughout the management process. Examples of uncertainties in the management of stuttering are seen throughout the literature relating to a lack of understanding the mechanism(s) of change in many interventions for PWS. For example, preschool CWS have shown to benefit from the Lidcombe Program [24-27], though we do not have definitive knowledge of how or why intentional verbal feedback is able to accomplish a reduction in disfluencies $[9,28,29]$. Furthermore, though prolongations are recognized as the current standard of care for PWS [30], its mechanism of change is not entirely understood [31]. Onken et al. [32] assert the need of understanding the underlying mechanism(s) behind an intervention in order to capitalize on the essential components. Accomplishing such for stuttering interventions would allow clinicians the ability to emphasize their use and would most likely result in a reduction of barriers and in increase in confidence in the management of stuttering. Therefore, it is possible that the selection of assessment tools and approaches taken by the SLPs in this sample are reflected in their overall lack of confidence in working with CWS, driven by general uncertainties of the nature and treatment of the disorder.

\section{Assessment tools}

The results of this survey indicated that versions of the Stut- 
tering Severity Instrument (SSI) were the most commonly utilized standardized assessment tool for CWS. Notably, of the $90 \%$ of the SLPs that used the SSI, $78 \%$ either used it as their sole instrument (41.9\%) or supplemented the SSI with only informal assessments (36.1\%). It is unclear whether the overwhelming selection of the SSI to evaluate CWS was related to: a) use of the tool during their training programs; b) mandates/recommendations by their school systems; or c) other personal reasons that were outside the scope of this survey. Regardless, it is notable that the primary focus of the Stuttering Severity Instrument - Fourth Edition (SSI-4) [33] is identification of overt behaviors of stuttering, and the severity rating that is specified by the SSI- 4 is comprised of only observable components. It may be possible that the SSI is more frequently utilized because overt behaviors are easier to identify with or without the tool and are in line with core knowledge related to stuttering behaviors. Consequently, using such an approach increases the likelihood of missing or underestimating unobservable covert behaviors.

There are implications for assessment approaches that rely heavily on the identification of overt behaviors. According to Manning and Beck [34], the percentage of stuttered syllables (i.e., observable behaviors) is not necessarily a reflection of the stuttering severity of PWS. Similarly, Constantino et al. [13] argued that frequency of stuttering is highly variable and varies substantially from situation-to-situation and from day-today. Therefore, frequency of stuttering (an observable behavior) should not be the primary indicator of stuttering severity. They suggest better criteria would be measures indicating impact on quality of life, which may be driven by the presence of avoidance behaviors (i.e., covert behaviors). Additionally, evidence suggests that overt stuttering severity is not strongly correlated with quality of life measures, potentially making impact on quality of life a salient and accurate measure regardless of overt stuttering severity level [5,35]. In summary, sole use of standardized measures such as the SSI may not address the comprehensive disability of stuttering. One potential consequence of an assessment approach that is focused primarily on observable behaviors is an under-identification of all facets of the experience of stuttering. For those individuals who are not diagnosed as a result, this may mean continued use of avoidance behaviors that do not facilitate communicative effectiveness [36-38]. Regardless, the most comprehensive understanding of the disorder's impact on the individual would potentially be achieved by utilizing a combination of assessment tools and/or methods that give equal consideration to both the observable and unobservable behaviors of stuttering.

\section{Overt-covert behavior considerations during assessments}

A key finding was that $80.6 \%$ of the sample indicated that observable disfluencies were needed in order to qualify a child for stuttering services. This finding was not limited to those SLPs with minimal experience, as there was no significant difference in those SLPs requiring the presence of disfluencies in order to qualify for services across years of experience. Among those who require observable disfluencies to qualify for stuttering services, the mean required percentage was nearly $13 \%$. A limitation of this finding was that the "percentage of disfluencies" was not operationally defined. However, as the general premise of this discussion suggests, reliance on any percentage of any disfluent lexical unit for qualification of services is not likely to give equal weight to the less conspicuous components of the disorder. To this point, nearly $21 \%$ of respondents do not give consideration to unobservable behaviors when qualifying a CWS for speech therapy. Furthermore, of the $79 \%$ of SLPs that do consider the covert behaviors of stuttering during assessments, $74 \%$ still require the presence of disfluencies in order for the CWS to qualify for services. That is, for the subgroup of SLPs who evaluate covert behaviors, such behaviors appear to be an added consideration and may not be weighted equally with those behaviors that are observable (e.g., repetitions and audible postural fixations). Consequently, for some CWS, limited consideration may be given to the impact potential resulting from avoidance practices that have been shown in the literature to be so detrimental - even for those people who stutter with the mildest overt symptoms [36,39].

Assessment approaches, and in particular consideration of observable and unobservable behaviors, are potentially influenced by theoretical/philosophical beliefs associated with clinical training and experience. As evidenced, some believe that the disorder only requires evaluation of its observable behaviors, yet the disorder in its totality consists of observable and unobservable behaviors. While unobservable behaviors tend to receive less attention, they may contribute the same level of disruption as observable behaviors during the stuttering experience [40]. The long-term consequence of approaches indicated by many in the current sample is that assessment approaches that primarily emphasize observable behaviors may impact treatment approaches. It is possible that therapies utilizing the unilateral approach of dealing 
solely with observable behaviors of stuttering may result in unresolved social anxieties, which in turn may lead to frequent avoidance behaviors [41,42], regardless of the acquired skills used to manage the observable behaviors.

Findings from the current project may provide insight into factors influencing SLPs' confidence levels. Data revealed significant differences when comparing confidence levels in the treatment of stuttering between those SLPs whose assessments include the evaluation of covert behaviors and those that do not. One potential contributor to SLPs' confidence in the treatment of CWS is the understanding of the disorder in its entirety (i.e., observable and unobservable behaviors). The literature has many examples of the impact of stuttering's unobservable behaviors on an individual $[4,36,39]$, and an SLP is likely to be confident if they observe a client making gains in both increased fluency and decreased avoidance behaviors. Likewise, their therapy approach is likely to be affirmed by their clients when such gains have been made. Further study is needed to clarify this issue.

\section{Limitations}

While results from this statewide survey of SLPs are informative, they are not free of limitations. First, the data reported here were obtained from a non-standardized survey. Nonstandardized surveys oftentimes do not effectively elicit the specific information intended [43]. Second, the survey did not include all SLPs in the state of NC, therefore some degree of caution must be applied with interpretation of these results. It is possible that non-respondents to the survey may have been far less confident than the respondents and elected to not participate in the survey process. Third, the survey did not allow respondents the opportunity to provide extensive details about questions being asked. Fourth, the authors acknowledge that the SSI-4 does include the Clinical Use of Self-Reports, which considers some aspects of the covert behaviors of stuttering, yet the SSI itself was referenced in this paper as being primarily an assessment of the observable behaviors due to how the severity rating is calculated. This should be considered in the interpretation of the survey results. Fifth, this survey included SLPs serving various age-ranges of CWS, which may impact some of the responses.

\section{CONCLUSIONS}

Data from this survey revealed that many SLPs in this sample lack, to some degree, confidence in managing CWS, which has direct clinical implications. The lack of confidence in managing CWS identified here suggests a continued need to understand the reasons behind this lack of confidence and continued work towards a more comprehensive understanding of the disorder in its entirety. Doing so will ultimately contribute to enhanced management practices and improved outcomes in CWS.

\section{Disclosures}

This research did not receive any specific grant from funding agencies in the public, commercial, or not-for-profit sectors.

\section{ACKNOWLEDGMENTS}

I wish to thank Dr. Charles Ellis for his comments/suggestions related to this work.

\section{REFERENCES}

1. Yairi E, Ambrose N. Epidemiology of stuttering: 21st century advances. Journal of Fluency Disorders. 2013;38:66-87.

2. Guitar B. Stuttering: an integrated approach to its nature and treatment. Lippincott Williams \& Wilkins; 2013 Jan 29.

3. Freeman FJ. Laryngeal muscle activity of stutterers. In: Curlee RF, Perkins WH editors. Nature and treatment of stuttering: new directions. San Diego, CA: College Hill Press, 1984. p. 104-116.

4. Jackson ES, Yaruss JS, Quesal RW, Terranova V, Whalen DH. Responses of adults who stutter to the anticipation of stuttering. Journal of Fluency Disorders. 2015;45:38-51.

5. Craig A, Blumgart E, Tran Y. The impact of stuttering on the quality of life in adults who stutter. Journal of Fluency Disorders. 2009; 34:61-71.

6. Yaruss JS, Coleman CE, Quesal RW. Stuttering in school-age children: a comprehensive approach to treatment. Language, Speech, and Hearing Services in Schools. 2012;43:536-548.

7. Nippold MA. When a school-age child stutters, let's focus on the primary problem. Language, Speech, and Hearing Services in Schools. 2012;43:549-551.

8. Blomgren M. Behavioral treatments for children and adults who stutter: a review. Psychology Research and Behavior Management. 2013;6:9.

9. Boucand VA, Millard S, Packman A, Donaher J, Minkoff C, Leahy $\mathrm{M}$, et al. Early intervention for stuttering: similarities and differences between two programs. Perspectives on Fluency and Fluency Disorders. 2014;24:8-19.

10. Gregg BA. Academic Training in Initial Counseling of Parents of Preschoolers who Stutter: a Simulated Caregiver Model. ProcediaSocial and Behavioral Sciences. 2015;193:123-130.

11. Kleinow J. Theory-based practice: a case study of the multifactorial model of stuttering. SIG 4 Perspectives on Fluency and Fluency 
Disorders. 2015;25:33-38.

12. Yaruss JS. Documenting treatment outcomes in stuttering: measuring impairment, disability, and handicap. 1998 [cited 2018 April 12]. Available from: http://www.mnsu.edu/comdis/isad/ papers/yaruss.html.

13. Constantino CD, Leslie P, Quesal RW, Yaruss JS. A preliminary investigation of daily variability of stuttering in adults. Journal of Communication Disorders. 2016;60:39-50.

14. American Speech-Language-Hearing Association. Stuttering. 2017 [cited 2018 April 12]. Available from: http://www.asha.org/ public/speech/disorders/stuttering/\#c.

15. Yaruss JS, Quesal RW. Stuttering and the international classification of functioning, disability, and health (ICF): an update. Journal of Communication Disorders. 2004;37:35-52.

16. Tellis GM, Bressler L, Emerick K. An exploration of clinicians views about assessment and treatment of stuttering. Perspectives on Fluency and Fluency Disorders. 2008;18:16-23.

17. Maviş İ, Louis KO, Özdemir S, Toğram B. Attitudes of Turkish speech and language therapists toward stuttering. Journal of Fluency Disorders. 2013;38:157-170.

18. Boyle MP. Understanding perceptions of stuttering among schoolbased speech-language pathologists: an application of attribution theory. Journal of Communication Disorders. 2014;5:52:143-155.

19. Lee K. Korean speech-language pathologists' attitudes toward stuttering according to clinical experiences. International Journal of Language \& Communication Disorders. 2014;49:771-779.

20. Gabel RM. School speech-language pathologists' experiences with stuttering: an Ohio survey. eHearsay. 2014;3:5-29.

21. North Carolina Guidelines for Speech-Language Pathology Services in Schools. Public Schools of North Carolina. 2006 [cited 2018 April 12]. Available from: http://ec.ncpublicschools.gov/disability-resources/speech-language-impairments/speech-guide. pdf.

22. Harris PA, Taylor R, Thielke R, Payne J, Gonzalez N, Conde JG. Research electronic data capture (REDCap) - a metadata-driven methodology and workflow process for providing translational research informatics support. Journal of Biomedical Informatics. 2009;42:377-381.

23. IBM Corp. IBM SPSS statistics for windows, version 22.0. Armonk, NY: IBM Corp. 2013.

24. Jones M, Onslow M, Packman A, O'Brian S, Hearne A, Williams S, et al. Extended follow-up of a randomized controlled trial of the Lidcombe Program of Early Stuttering Intervention. International Journal of Language \& Communication Disorders. 2008;43:649661.

25. Lattermann C, Euler HA, Neumann K. A randomized control trial to investigate the impact of the Lidcombe Program on early stuttering in German-speaking preschoolers. Journal of Fluency Disorders. 2008;33:52-65.

26. O’Brian S, Iverach L, Jones M, Onslow M, Packman A, Menzies R.
Effectiveness of the Lidcombe Program for early stuttering in Australian community clinics. International Journal of Speech-Language Pathology. 2013;15:593-603.

27. Guitar B, Kazenski D, Howard A, Cousins SF, Fader E, Haskell P. Predicting treatment time and long-term outcome of the Lidcombe Program: a replication and reanalysis. American Journal of Speech-Language Pathology. 2015;24:533-544.

28. Ratner NB. Evidence-based practice in stuttering: some questions to consider. Journal of Fluency Disorders. 2005;30:163-188.

29. Hayhow R. Does it work? Why does it work? Reconciling difficult questions. International Journal of Language \& Communication Disorders. 2011;46:155-168.

30. Ingham RJ, Ingham JC, Bothe AK, Wang Y, Kilgo M. Efficacy of the modifying phonation intervals (MPI) stuttering treatment program with adults who stutter. American Journal of Speech-Language Pathology. 2015;24:256-271.

31. Brown L, Wilson L, Packman A, Halaki M, Onslow M, Menzies R. An investigation of the effects of a speech-restructuring treatment for stuttering on the distribution of intervals of phonation. Journal of Fluency Disorders. 2016;50:13-22.

32. Onken LS, Carroll KM, Shoham V, Cuthbert BN, Riddle M. Reenvisioning clinical science: unifying the discipline to improve the public health. Clinical Psychological Science. 2014;2:22-34.

33. Riley GD, Bakker K. Stuttering severity instrument: SSI-4. Pro-Ed; 2009.

34. Manning W, Beck JG. The role of psychological processes in estimates of stuttering severity. Journal of Fluency Disorders. 2013;38: 356-367.

35. Tran Y, Blumgart E, Craig A. Subjective distress associated with chronic stuttering. Journal of Fluency Disorders. 2011;36:17-26.

36. Petrunik M, Shearing CD. Fragile facades: stuttering and the strategic manipulation of awareness. Social Problems. 1983;31:125138.

37. Murphy B, Quesal RW, Gulker H. Covert stuttering. Perspectives in Fluency and Fluency Disorders. 2007;17:4-9.

38. Erickson S, Block S. The social and communication impact of stuttering on adolescents and their families. Journal of Fluency Disorders. 2013;38:311-324.

39. Starkweather CW. Fluency and stuttering. Prentice-Hall, Inc; 1987.

40. Yaruss JS. Assessing quality of life in stuttering treatment outcomes research. Journal of Fluency Disorders. 2010;35:190-202.

41. Iverach L, Rapee RM. Social anxiety disorder and stuttering: current status and future directions. Journal of Fluency Disorders. 2014;40:69-82.

42. Iverach L, Rapee RM, Wong QJ, Lowe R. Maintenance of social anxiety in stuttering: a cognitive-behavioral model. American Journal of Speech-Language Pathology. 2017;26:540-556.

43. Fowler Jr FJ. Survey research methods. Sage publications; 2013 Sep 18. 


\section{APPENDIX}

\section{CLINICIAN BACKGROUND}

1 Did your graduate training include a course solely dedicated to fluency disorders?

2 How many years have you been a practicing SLP?

\section{CASELOAD CHARACTERISTICS}

3 What is the average size of your caseload for a school year?

4 In total, how many children who stutter (CWS) are currently on your caseload?

5 What percentage of the CWS on your caseload would you classify as mild? - if unable to answer, explain:

6 What percentage of the CWS on your caseload would you classify as moderate?

- if unable to answer, explain:

7 What percentage of the CWS on your caseload would you classify as severe? - if unable to answer. explain:

\section{CONFIDENCE IN WORKING WITH PEOPLE WHO STUTTER}

8 How confident do you feel when screening for the presence of stuttering?

How confident do you feel when evaluating for the presence of stuttering?

10 How confident do you feel when treating a CWS?

\section{ASSESSMENT AND TREATMENT OF STUTTERING}

11 How many screenings have you conducted in the past 12 months for suspected children who stutter?

- if unable to answer, explain:

12 How many evaluations have you conducted in the past 12 months for suspected children who stutter?

- if unable to answer, explain:

13 What tools do you use when evaluating stuttering? (Check all that apply)

14 Do you evaluate covert behaviors (i.e., avoidances of sounds, words, people, places, and situations) when qualifying a CWS for speech services?

15 Do you assign severity to covert behaviors (i.e., avoidances of sounds, words, people, places, and situations) when diagnosing stuttering in children?

16 A CWS must present with what percent of disfluencies to qualify for therapy?

17 In your experience, what role do parents play in the evaluation and treatment of children who stutter?

18 When a CWS is discharged from therapy, are you satisfied with the outcome? - explain why or why not:
Yes

No

Years

Years
Students/clients
Students/clients
$\%$ Students/clients classified as mild
$\%$ Students/clients classified as moderate
$\%$ Students/clients classified as severe

a. Not at all confident

b. Somewhat confident

c. Extremely confident

a. Not at all confident

b. Somewhat confident

c. Extremely confident

a. Not at all confident

b. Somewhat confident

c. Extremely confident 